\title{
Transparente Prozesse durch moderne ERP-Software
}

\author{
Mehr Transparenz für seine internen Betriebsprozesse wünschte sich das Unternehmen \\ Metallbeschichtung Resch. Durch die Umstellung auf eine moderne ERP-Software konnten der \\ Erfassungsaufwand gesenkt, Neben- und Rüstzeiten minimiert und die Produktivität gesteigert werden.
}

$D^{a}$ as Unternehmen Metallbeschichtung Resch wurde im Jahr 1974 gegründet und verfügt über große Erfahrungen im Bereich der Pulverbeschichtung. Zur Optimierung der Prozesse im Unternehmen entschied sich Geschäftsführer Karsten Schreiber für eine moderne ERP-Software vom Typ avista. ERP des Softwareherstellers Avista.

Die Problemstellung innerhalb der Angebotskalkulation war, dass im abgelösten System Preiskalkulationen manuell in einer Nebenrechnung erstellt werden mussten und nicht abgespeichert werden konnten. In der neu installierten Software ist ein einfach $\mathrm{zu}$ bedienender Konfigurator eingebaut, der es jedem Mitarbeiter ermöglicht, mit Hilfe der hinterlegten Parameter den Angebotspreis zu ermitteln. Die Suche nach den Angebotspositionen ist wesentlich vereinfacht, so dass der Verwaltungsaufwand entscheidend reduziert werden konnte.

Auch die Zuordnung der angelieferten zu beschichtenden Teilen war bisher eine Herausforderung. Die Neuerung liegt darin, dass jede Wareneingangsposition ein Barcodeetikett erhält, das diese Position eindeutig identifiziert. Über einen mobilen Online-Barcodescanner kann jeder Behälter im Wareneingangslager eindeutig identifiziert und zugeordnet werden. Durch die Transparenz im neuen ERPSystem kann auch die Weiterverarbeitung eines Angebots über Auftrag, Lieferschein bis zur Rechnung von jedem Mitarbeiter ohne Spezialwissen durchgeführt werden.

\section{Materialbewegungen jederzeit erfassen}

In Bezug auf die Lagerhaltung und Farbdisposition der 2500 verschiedenen Farbpulver führte Avista eine dynamische Lagerhaltung ein. Alle Materialbewegungen werden mit Artikel, Menge und Lagerplatz über einen mobilen Online-Barcodescanner durchgeführt. Jetzt ist eine Materialverfügbarkeitsprüfung jederzeit möglich. Das Ergebnis ist ein deutlich reduzierter Aufwand für Ein- und Auslagerung, eine exakte Bestandsführung und eine Bestellvorschlagsliste unter Berücksichtigung der Auftragssituation.
Resch-Geschäftsführer Karsten Schreiber ist mit dem Ergebnis zufrieden. Neben der Angebotskalkulation, Auftragserfassung- und bearbeitung, Lagerhaltung und Farbdisposition wurde die Fertigungsauftragssteuerung mit der Einführung der neuen Software entscheidend verbessert und automatisiert.

Entscheidend ist für ihn auch die Reduzierung der Rüstzeiten durch die nach Farben optimierte Fertigungsplanung der Anlagen, die vor Einführung des neuen Systems ebenfalls manuell gesteuert wurden. Es gab mehr Farbwechsel als eigentlich notwendig waren, da kein vollständiger Überblick über die Aufträge nach Terminen und Farben möglich war. Resch benötigt für die Produktion eine sinnvolle Gruppierung seiner Aufträge. Aus den Parametern der Auftragsposition (Termin, Farbe, Kapazitätsbedarf) kann nun über die Auftragssteuerung die bestmögliche Reihenfolge ermittelt werden. I

\section{Kontakt:}

Avista ERP-Software GmbH \& Co. KG, Stuttgart, Tel.0711 1353300, info@avista-erp.de, www.avista-erp.de

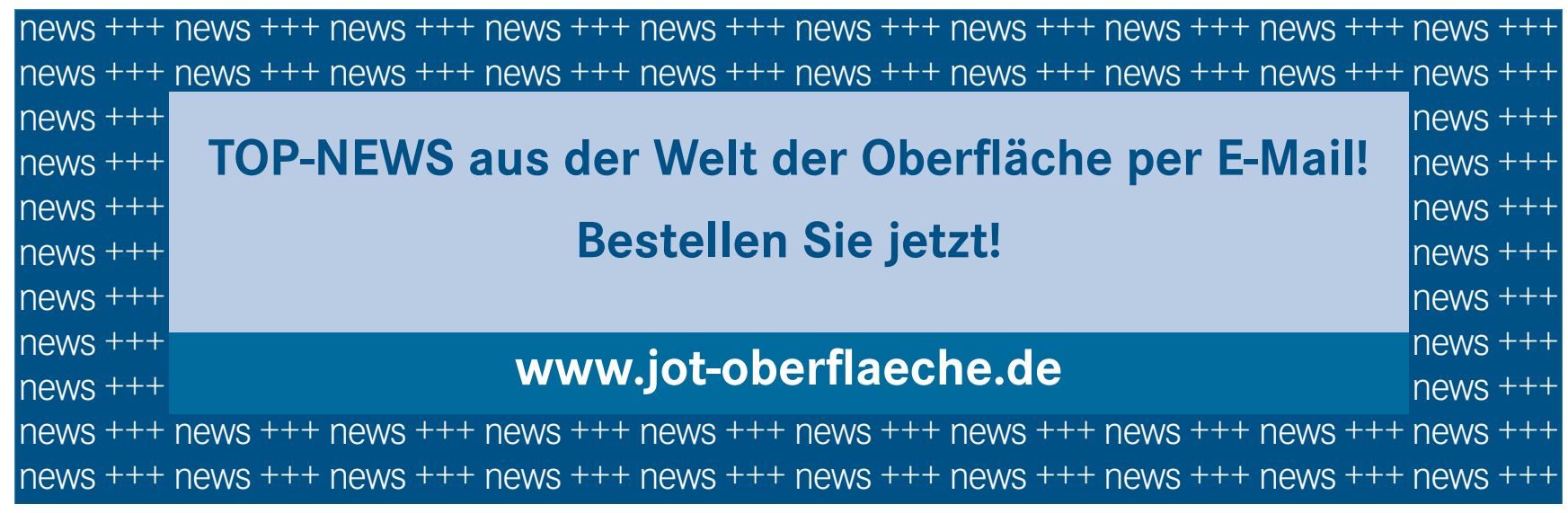

